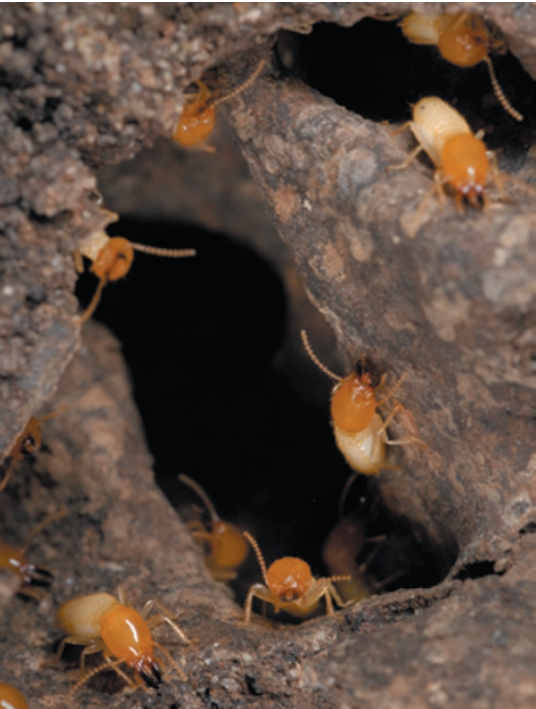

Thomas Chouvenc and his colleagues at the University of Florida in Fort Lauderdale report another such defence mechanism: the mixture of wood pulp and faeces that lines Coptotermes' nests (pictured) supports bacteria that have antimicrobial activity, including a Streptomyces species that is effective against Metarhizium. The bacterium gave termites a considerable survival advantage in soil that harboured the fungus.

Interfering with this mutually beneficial insectbacterium relationship might aid pest control, and termite faeces could also be an untapped source of medicines that protect against infection, the authors say.

Proc. R. Soc. B 280, 20131885 (2013)

\section{EVOLUTION}

\section{Cool eggs make for longer legs}

Incubating eggs of the tropical skink (Carlia longipes; pictured) at different temperatures results in hatchlings with legs adapted for different terrains.

Brett Goodman, now at the University of Adelaide in Australia, and his colleagues caught female skinks living in a mixed habitat of forest and

3

rocks. These lizards lay clutches of two eggs, and the researchers split 76 sets of sibling eggs to incubate at temperatures reflecting either the forest floor (about $28.5^{\circ} \mathrm{C}$ ) or rock surfaces (about $23.5^{\circ} \mathrm{C}$ ).

Eggs incubated at the cooler temperature hatched into long-legged skinks that could sprint and climb more quickly than their warm-incubated siblings. When given a choice, the cool-incubated skinks spent more time in rocky areas, whereas skinks incubated at the warmer temperature had shorter legs and preferred leaf litter.

Am. Nat. http://dx.doi. org/10.1086/673299 (2013)

\section{PHYSICAL CHEMISTRY}

\section{Vitamin coating blocks static}

The familiar phenomenon of static electricity can cause serious problems, such as explosions and equipment damage.

A team led by Bartosz Grzybowski at Northwestern University in Evanston, Illinois, has found an explanation for how static electricity builds up, along with a simple way to dissipate it.

The researchers examined magnetic and electric patterns on polymer surfaces using specialized forms of atomic force microscopy. This revealed that clumps of charged particles owe their stability to chemical species known as radicals - reactive molecules with unpaired electrons.

Further experiments showed that these radicals could be mopped up by surface coatings, including vitamin $\mathrm{E}$ and other antioxidants. Coated polystyrene beads quickly lost their static charge, and a coated transistor resisted damage

COMMUNITY CHOICE

\title{
Lab rats reveal genetics of selection
}

\section{HIGHLY READ \\ on www.cell.com in September}

DNA sequencing is illuminating the genetic underpinnings of 27 rat strains bred to study human diseases.

Since the early 1900s, researchers have selected and bred rats displaying traits such as hypertension and behavioural disorders, producing hundreds of distinct strains. Researchers led by Timothy Aitman at Imperial College London sequenced the complete genomes of several common strains of laboratory rat, revealing more than 13 million genetic variants as well as evidence for the evolutionary pressures behind them. A strain known for its cardiovascular disorders, for example, showed specific selection for gene clusters that are involved in regulating blood pressure and oxidative stress.

Further analysis of how artificial selection created rat models of disease should point to genetic variations and mechanisms that contribute to human maladies. Cell 154, 691-703 (2013)

from an ion gun.

Science 341, 1368-1371 (2013)

For a longer news story on this work, see go.nature.com/ejdpy1

\section{CLIMATE \\ Waiting to reduce emissions is costly}

If international efforts to reduce carbon emissions are delayed by another 15 years, the initial costs of limiting global warming could triple.

Gunnar Luderer at the

Potsdam Institute for Climate Impact Research in Germany and his colleagues used a model to study 285 mitigation scenarios. They calculated the costs incurred within the first few years after implementing policies to hold temperatures to $2{ }^{\circ} \mathrm{C}$ above pre-industrial levels.

If such policies come into force in 2030 or later, energy prices are likely to shoot up by $80 \%$ and global economic growth might decrease by $7 \%$ in the decade following implementation.

Broad emissions reductions need to start in 2015 to keep costs moderate, the authors say. Environ. Res. Lett. 8, 034033 (2013)

\section{DIAGNOSTICS \\ Virus revealed by host response}

A straightforward test of human immune responses can show whether flu-like symptoms arise from bacterial or viral infection.

A team led by Christopher Woods and Geoffrey Ginsburg of Duke University in Durham, North Carolina, developed an assay based on a technique called RT-PCR, which can measure gene expression in blood samples.

The assay monitors roughly 30 human genes that have differing activities in bacterial and viral infections. When used on 102 people who came to a hospital with fevers and respiratory symptoms, the test identified a viral infection with $94 \%$ accuracy and could exclude a viral cause with $89 \%$ accuracy.

Sci. Transl. Med. 5, 203ra126 (2013)

\section{$\rightarrow$ NATURE.COM}

For the latest research published by Naturevisit:

www.nature,com/latestresearch 